\title{
Heat adaptation measures in private households: an application and adaptation of the protective action decision model
}

Sabrina Katharina Beckmann (10 ${ }^{1 凶}$, Michael Hiete ${ }^{1}$, Michael Schneider ${ }^{2} \&$ Christoph Beck $^{3}$

Extreme heatwaves will occur more frequently and with higher intensity in future. Their consequences for human health can be fatal if adaptation measures will not be taken. This study analyses factors related to heat adaptation measures in private households in Germany. During the summer months of 2019, indoor temperatures were measured in over 500 private households in the City of Augsburg, Germany, accompanied by a survey to find out about heat perception and adaptation measures. Hypotheses deducted from the Protective Action Decision Model were tested using one-way ANOVAs, regression analysis and in the end a multiple hierarchical regression model. The results of the hypotheses tested imply an influence of knowledge and heat risk perception of heat adaptation behaviour and an influence of age on heat risk perception. The results of the regression model show an influence of the efficacy-related attribute, of age, indoor temperature, subjective heat stress and health implications to heat adaptation behaviour. In the end, this study proposes adjustments to the PADM according to the results of the hierarchical regression analysis.

\footnotetext{
${ }^{1}$ Department of Business Chemistry, Ulm University, Ulm, Germany. ${ }^{2}$ Bifa Environmental Institute, Augsburg, Germany. ${ }^{3}$ Augsburg University, Institute of

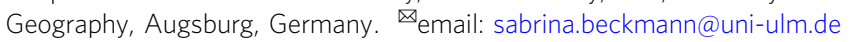




\section{Introduction}

he probability of hazardous heatwaves caused by climate change is rising steadily (IPCC, 2019). By 2100, the exposure to extremely high temperatures is expected to be four to eight times higher than in the 2010s (Wang et al., 2020). Additionally to the rising temperatures, the latest revision of the World Urbanization Prospects by the United Nations suggests that by 2050 almost $70 \%$ of the world's population will live in urban areas (United Nations, Department of Economic and Social Affairs, Population Division, 2019) which results in urban heat islands with a very slow heat release overnight (Manoli et al., 2019). This is an extreme challenge for cities and communities as research has shown the association between human mortality and heatwaves and how the growing risk for human life seems inescapable in future (Mora et al., 2017).

At the same time, studies imply that heat wave and health impact research is necessary, especially in regions that are not experienced extreme temperatures during the summer months (Campbell et al., 2018). According to the 2020 report of The Lancet Countdown on health and climate change (Watts et al., 2020), heat has caused a $50 \%$ increase in global heat-related deaths among people over 65 years from 2000 to 2018. In the summer of 2018 , there were over 20,000 cases of death caused by heatwaves in Germany alone according to model calculation. Additionally, the rising frequency and intensity of heatwaves are causing a rising probability of new infectious diseases (Watts et al., 2020). Therefore, in the literature, there are calls for taking more adaptation measures and developing strategies for protecting people from high-temperature exposure, especially during nighttime (Zhao, 2018; Alcoforado et al., 2015).

Studies aiming to explain heat adaptation behaviour found that risk perception has an influence (Esplin et al., 2019; Kim et al., 2014; Wolf et al., 2010), as well as being female or of older age (Esplin et al., 2019; Khare et al., 2015; Kim et al., 2014; Semenza et al., 2008). Other factors are income and education (Esplin et al., 2019; Khare et al., 2015; Semenza et al., 2008) as well as the social network around individuals (Klinenberg, 2015). However, protective behaviour against heatwaves is a complex construct. Climate change adaptation in general aims to reduce risks for vulnerable groups and increase their resilience to climate change consequences (Smit and Pilifosova, 2001). Wolf et al. (2010) examine the consequences of adaptation behaviour in preventing morbidity and mortality caused by heatwaves. In 2018, a study found that in German households the probability of adaptation behaviour rises by $2.3 \%$ for every degree celsius the mean temperature during summer is rising (Kussel, 2018).

Still, adaptation behaviour in private households in Germany is relatively low and often heat is not seen as a health risk. Especially the older generation shows lower perception of heat as a risk (Beckmann and Hiete, 2020) as well as lower subjective heat stress (SHS) (Beckmann et al., 2021) despite being part of a vulnerable group. Kussel (2018) found that the elderly also show lower probability to adapt. Therefore, policy should mainly aim to communicate among such vulnerable groups (Kussel, 2018). However, data on taken adaptation measures in private households, as well as on indoor temperatures is rather scarce. Even though knowing about influencing factors of adaptation behaviour-not only amongst vulnerable groups-leads to a better intervention against climate change consequences (WhiteNewsome et al., 2011).

Several theoretical frameworks were applied in previous studies about heat or climate change adaptation behaviour such as the Theory of Planned Behaviour (TPB) (Valois et al., 2020), the Health Belief Model (HBM) (Akompab et al., 2013), the Value Belief Norm (VBN) (Zhang et al., 2020) or the Protection
Motivation Theory (PMT) (Murtagh et al., 2019). This study applies the Protective Action Decision Model (PADM), a theoretical framework that so far has not been applied in heat risk and heat adaptation literature, to shed light on people's heat adaptation behaviour. The availability of indoor bedroom temperatures of private households in this study requires a theoretical model that includes external stimuli or the exposure to a certain hazard (in this case heat) in the evaluation of influences on adaptation behaviour. The PADM includes this factor. The authors are not aware of a study that applies the PADM to heat adaptation behaviour. The results show which factors influence the implementation of heat protection measures in private households and give guidance on to whom communication should be directed in the first line.

\section{Background theory}

This section introduces theories that have been applied to heat adaptation or climate change adaptation behaviour and point out the differences and advantages of applying the PADM.

A very commonly applied theory is the $T P B$. It has recently been applied to investigate climate change adaptation in agricultural production while being compared to the VBN (Zhang et al., 2020), for heat adaptation behaviour in the elderly population (Valois et al., 2020), political ideology and threat perception that affects climate adaptation decisions (Schwaller et al., 2020) and for the link between knowledge and climate change adaptation among German forest owners (Hengst-Ehrhart, 2019). The TPB is an extension of the Theory of Reasoned Action both co-developed by Icek Ajzen. According to the TPB, the factors of attitude and perceived behavioural control, together with a person's subjective norm, create the individual intention for a specific behaviour. Thus, a person's perceived behavioural control together with his or her intention leads to a specific behaviour (Ajzen, 1991). The TPB has proven to be adequate for climate change adaptation studies and pro-environmental behaviour studies, including extending it by factors like moral obligation (Bamberg and Möser, 2007; Chen, 2016) or socioeconomic and communication variables (Arunrat et al., 2017).

The $V B N$ is another framework found in the literature. It has commonly been used to analyse pro-environmental behaviour in various settings (Chen, 2016; Wynveen et al., 2015; Kim and Shin, 2017; Çakır Yıldırım and Karaarslan Semiz, 2019); whereas applications for climate change adaptation are scarce. One of the studies has been mentioned in the paragraph before together with the TPB (Zhang et al., 2020). Another example is Yousefpour et al. (2019) who applied the VBN to climate change adaptation in Singapore focussing on the rise of sea level. Literature, however, shows that risk perception is an important factor for climate change adaptation behaviour (Kalkstein and Sheridan, 2007). This factor is not part of the initial VBN model.

The HBM is another framework that can be found in climate change adaptation literature. In 2011, Semenza et al. applied the HBM to analyse a survey of 771 people in the United States with respect to the motivation for adaptation and mitigation to climate change in general. Akompab et al. (2013) applied the HBM on predictors for risk perception and adaptive behaviour during heat waves in Australia. Another study investigating adaptation to and perception of heatwaves and applying the HBM is Rauf et al. (2017). The HBM explains the likelihood of taking preventive health action through the factors related to individual perceptions (perceived susceptibility and perceived severity) that lead to perceived threat and modifying factors (demographic variabilities, perceived threat and cues to action) (Rosenstock, 1974). The 


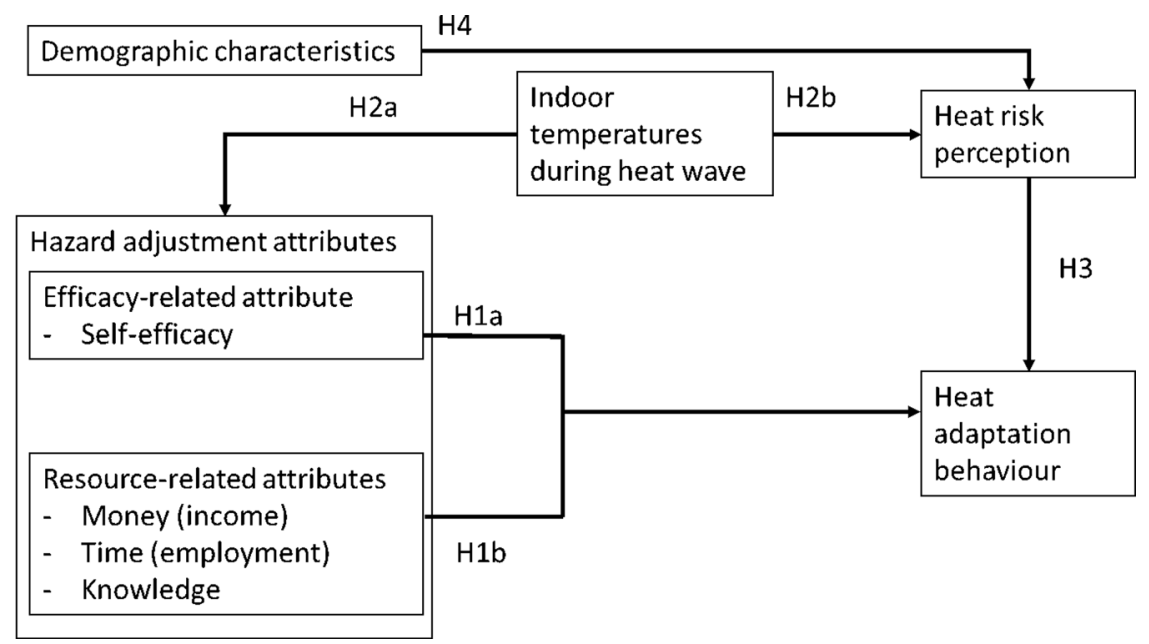

Fig. 1 The PADM applied to heat adaptation behaviour in this study referring to Terpstra and Lindell (2013). Figure shows flow of information in the PADM. Boxes show variables, arrows show deduced hypotheses.

HBM is widely used to explain health-related actions. However, the current study aims to include external stimuli (exposure in terms of indoor temperature).

The VBN is commonly used in literature predicting behaviour and the TPB, as well as the HBM, are established theoretical models when it comes to climate change adaptation. However, all three of them lack the inclusion of external influences, hence also the external stimuli. When it comes to heat risk adaptation behaviour, the external stimulus (high temperature) is a necessary factor that should be paid attention to.

Another framework worth noting, as it is often used to analyse climate change adaptation is the PMT. Recent research applied PMT to explain adaptation behaviour to extreme weather events (Budhathoki et al., 2020), the relation of climate change adaptation and gender (Goli et al., 2020) and the motivation to protect building stocks from climate-related overheating (Murtagh et al., 2019). The PMT combines a person's threat appraisal (that is the probability and severity of a threat) with one's coping appraisal (self-efficacy, response-efficacy and cost) to explain the intention of motivation to take protective action (Rogers, 1975). However, as other studies point out, knowledge is an important influencing factor for climate change adaptation behaviour (Birkmann and von Teichman, 2010). Therefore, in the current study it is necessary to include knowledge as a variable in the framework.

The Protective Action Decision Model initially was established to explain people's decision to take protective actions to hazards and risks (Lindell and Perry, 1992). In 2012, Lindell and Perry extended the model to explain long-term adjustment. They use variables explaining efficacy related ('hazard-related') and adjustment-related ('resource-related') attributes to explain adaptation behaviour (Lindell and Perry, 2012). In the model by Lindell and Perry, efficiency-related attributes (ERAs) include the efficacy for protecting people, property and other purposes. Adjustment-related attributes include the amount of money, time, knowledge and skills required. Based on these characteristics and the fact, that the PADM has been successfully applied to other natural hazards before, this study applies PADM to model heat adaptation behaviour. The depiction of the model for this study is shown in Fig. 1 in the section 'Hypotheses'.

\section{Method}

Research design. The research area in this study is the city of Augsburg, Germany. There are nearly 300,000 inhabitants living in Augsburg, Germany in an area of $147 \mathrm{~km}^{2}$. For the period 1981-2010, the average temperature in July, the hottest month of the year, was $18.1^{\circ} \mathrm{C}$ and the annual mean temperature was $8.5^{\circ} \mathrm{C}$ (Deutscher Wetterdienst, 2019). During that climate period, there were only 6 days per year with maximum temperatures above $30{ }^{\circ} \mathrm{C}$ (Deutscher Wetterdienst, 2019). In this context, it is interesting and important to keep in mind that the number of hot days in recent summers has risen dramatically: 12 hot days in 2018, as well as in 2019; 11 hot days in 2017, eight hot days in 2016. During the survey period from July 1, 2019, to September 1 , 2019 , the highest temperature was $34.4^{\circ} \mathrm{C}$, measured on July 25 (Deutscher Wetterdienst, 2020). During the summer months of 2019, indoor temperatures were measured in private households and a questionnaire survey was carried out as part of the project 'Augsburg stays cool' (Projekt Augsburg bleibt cool, 2019). The overall objective of the project was to identify heat hotspots in the urban area, raise awareness of heat risks among citizens and develop heat adaptation measures for the city. In the survey, enquiries were raised regarding heat risk perception, knowledge and taken or planned adaptation measures, but also regarding sociodemographic details such as age, education, gender and personal information, such as chronic diseases or health-related problems during heatwaves. Data collection was conducted among participants who signed up to place a temperature data logger in their bedrooms to measure indoor temperatures during summer 2019. The research area was chosen by allocating the city into local climate zones (LCZs; Beck et al., 2018). A cross-section was drawn over the city to ensure the inclusion of as many LCZs as possible. Citizens living in the research area obtained an invite to contribute to the project and to receive the temperature data logger. According to the manufacturer, the distributed loggers (Elitech RC-5) have an accuracy of $\pm 0.5^{\circ} \mathrm{C}$ (Elitech, 2020). Accompanying the data logger, registered participants got access to the online survey; alternatively, they could choose a telephone interview. The survey was taken in German language and the results were translated into English for publication. Whenever possible, constructs were taken from studies in the German language to avoid possible shifts in meaning by translating them. Hereby, 431 datasets were collected containing both, the indoor temperature during summer and personal information through completed questionnaires. Even though the temperature was measured in bedrooms, the questionnaires likely were answered by one household member only, hence the registered participant. 
Measures. A total of 431 datasets were obtained containing both, indoor temperature and personal information from the survey in the German language. Table 1 shows the base rate of the population and the data sample size. $250(60.4 \%)$ of the participants are female and $164(39.6 \%)$ are male. More details about social characteristics are shown in the section 'Descriptive statistics' below. The questionnaire contained 35 questions and was designed to investigate heat risk perception, personal heat stress, knowledge and adaptation behaviour.

PADM constructs. Following Lindell and Perry (2012), the PADM describes how adaptation decisions protecting from environmental hazards are usually taken. The constructs used in this study to investigate heat adaptation behaviour are described in the following section.

Heat adaptation behaviour. To find out about adaptive behaviour and the intention to adapt to heatwaves, participants were first asked to rate five adaptation measures for their private household according to the likeliness of taking these measures. The five possible adaptation measures were buying air conditioning, installing more inside blinds or outside shadings, installing more green or blue areas around the house or on the balcony, buying a fan, moving into a cooler house or city. Additionally to those optional adaptation measures, participants were asked which adaptation behaviour they already apply during a heatwave to ensure adequate sleeping quality. The statistics of heat adaptation behaviour is shown in Table 2. To conduct statistical hypothesis tests, the adaptation measures were summarized in an Adaptation Behaviour Score by dichotomizing all answers into is an option/is

\begin{tabular}{|lcc|}
\multicolumn{3}{l}{ Table $\mathbf{1}$ Base rate of population and sample size (Source: } \\
Statistical Source from Augsburg, Germany, 2020). \\
Criteria & Total 2019 & $\boldsymbol{n}$ in this study \\
\hline Citizens & 299.620 & 427 \\
Female & $151.301(50.5 \%)$ & $260(60.9 \%)$ \\
Male & $148.319(49.5 \%)$ & $167(39.1 \%)$ \\
Under 18 & $45.661(15.2 \%)$ & - \\
18-29 & $55.633(18.6 \%)$ & $97(22.7 \%)$ \\
30-64 & $141.360(47.2 \%)$ & $263(61.6 \%)$ \\
Above 65 & $56.966(19 \%)$ & $67(15.7 \%)$ \\
People living alone & $84.310(28.1 \%)$ & $152(35.6 \%)$ \\
\hline
\end{tabular}

already taken' $=1$ and 'is not an option/is not taken' $=0$ and summarizing data into one score (mean $(M)=6.15$, standard deviation $(\mathrm{sd})=1.65)$.

Risk perception. Risk perception is known to be an influencing factor for adaptive behaviour to environmental hazards. It is part of the PMT (Threat Appraisal) as well as the PADM. In this study, heat risk perception constructs were based on previous studies (Rauf et al., 2017; Akompab et al., 2012).

To find out about heat risk perception and its relation to the perception of other natural hazards, the items from Martens et al. (2014) were used. The items can be found in the database of the GESIS-Leibniz Institute for the Social Science-(Leibniz-Institut für Sozialwissenschaften, 2021) in the German language, as used in the questionnaire, and have already been tested and validated. Two of the eight statements were modified to ask about (a) heat risk perception for the individual and (b) for his/her environment. The items were rated on a 4-point Likert scale ( 1 ='strongly disagree', 2 ='disagree', 3 = 'agree', $4=$ 'strongly agree') and later summarized to a Heat Risk Perception Score. An overview is given in Table 3.

Hazard adjustment attributes. The hazard adjustment attributes consist of the ERA and resource-related attributes (RRA). In this study, ERA is measured by the internal locus of control (LOC) of reinforcement. The construct plays an important role in

\section{Table 3 Heat Risk Perception item and statistics.}

\begin{tabular}{llll} 
Item & n & M & sd \\
\hline 'I think that heatwaves endanger my personal & & 2.42 & 1.06 \\
health' & & & \\
Strongly disagree & 95 & & \\
Disagree & 154 & & \\
Agree & 89 & & \\
Strongly agree & 93 & 3.28 & 0.84 \\
'Heat waves threaten plants and animals' & & \\
Strongly disagree & 7 & & \\
Disagree & 87 & 115 & \\
Agree & 222 & & \\
Strongly agree & & \\
\hline M mean, sd standard deviation. & & \\
Cronbach's $\alpha=0.66$. & & \\
\hline
\end{tabular}

Table 2 Overview of heat adaptation measures and behaviour.

\begin{tabular}{|c|c|c|c|c|}
\hline & \multicolumn{2}{|c|}{ Is an option/is already taken } & \multicolumn{2}{|c|}{ Is not an option/is not taken } \\
\hline & $n$ & $\%$ & $n$ & $\%$ \\
\hline \multicolumn{5}{|l|}{ Adaptation measure } \\
\hline Buying air conditioning & 122 & 28.3 & 309 & 71.7 \\
\hline More shadings (inside/outside) & 340 & 78.9 & 91 & 21.1 \\
\hline More green/blue around the house & 323 & 74.4 & 108 & 25.6 \\
\hline Buying fan & 271 & 62.9 & 160 & 37.1 \\
\hline Moving into cooler house/city & 196 & 45.5 & 235 & 54.5 \\
\hline \multicolumn{5}{|l|}{ Adaptation behaviour } \\
\hline Using thin/no bedding & 368 & 85.4 & 63 & 14.6 \\
\hline Using thin/no nightwear & 359 & 83.3 & 72 & 16.7 \\
\hline Taking showers at night & 73 & 16.9 & 358 & 83.1 \\
\hline Putting up wet cloths at open window & 21 & 4.9 & 410 & 95.1 \\
\hline Keep window open during night time & 353 & 81.9 & 78 & 19.1 \\
\hline Airing bedroom before sleeping & 199 & 46.2 & 232 & 53.8 \\
\hline Sleeping at a cooler place & 27 & 6.3 & 404 & 93.7 \\
\hline
\end{tabular}


predicting and explaining an individual's behaviour and-in this case-the convincement and, therefore, the willingness to take adaptation measures. The internal LOC describes the extent to which participants think they control events happening in their lives and experience them as a consequence of their own behaviour. The external LOC is defined as the extent to which an individuum thinks everything happening in his or her life depends on destiny or fate or is under the control of others (Kovaleva et al., 2014; Levenson, 1973; Rotter, 1966). The statements used to find out about the LOC in the questionnaires are shown in Table 4. Responses were given on a 5-point Likert scale ( $1=$ 'I totally agree'; $5=$ 'I do not agree at all'). The two items were summarized to one score.

The RRAs were measured by asking participants about their available resources to adapt. Those are the available amount of financial resources (household income), the available amount of time (employment/unemployment) and knowledge about heatwaves.

Knowledge about heat risks was operationalised in ten statements about heatwave risks; these statements were partly adopted from Rauf et al. (2017) and partly completed by statements taken from the information in Bunz and Mücke (2017). Table 5 shows the 10 statements including the number of participants that answered the statements correctly. The choices of answers were 'true', 'false' or 'I don't know', leading to an overall knowledge score.

Risk area. As Esplin et al. (2019) pointed out, in order to protect citizens in certain urban areas, it is essential to pay attention to spatial variations as heat exposure may vary from area to area. In

\section{Table 4 Efficacy-related attributes items and statistics.}

\begin{tabular}{llll} 
Item & n & M & sd \\
\hline 'I am in control of my own life' & & 4.48 & 0.71 \\
Totally agree & 255 & & \\
Agree & 138 & & \\
Partly & 31 & & \\
Disagree & 6 & & \\
Totally disagree & 1 & & \\
'If I make an effort, I will succeed' & & 4.28 & 0.77 \\
Totally agree & 192 & & \\
Agree & 182 & & \\
Partly & 46 & & \\
Disagree & 9 & & \\
Totally disagree & 2 & & \\
\hline Cronbach's $\alpha=0.6$. & & & \\
$M$ mean, sd standard deviation. & & \\
\hline
\end{tabular}

this case, indoor heat exposure varies from household to household and is measured by actual indoor temperature during the summer months. The distributed temperature data loggers recorded indoor temperature in bedrooms every $15 \mathrm{~min}$ during July and August 2019. For this study, the temperature during a 3 days heatwave in Augsburg, Germany from 24 to 26 July 2019 is used. The overall mean indoor temperature (day and night) during this heatwave was $27.14^{\circ} \mathrm{C}$, sd $=1$.6. Table 6 summarizes the mean temperatures.

Other influencing factors. Additionally to the prior introduced factors that are included in the PADM and will be tested in hypotheses, there are further variables identified in the literature affecting heat or climate adaptation behaviour in the literature. One of those is the health symptoms a person experiences during extreme weather events (Esplin et al., 2019; Kim et al., 2014). In this study, a health implication score (HIS) will be included in later analyses, generated from seven questions about health implications experienced during heat waves. Answers were given according to the frequency of health implications occurring from $1=$ 'never', 2 ='sometimes', $3=$ 'often'. The possible health implications included in the questionnaire were: drowsiness $(M=2.1, \quad s d=0.64)$, sleeping problems $(M=2.1, s d=0.69)$, concentration problems $(M=2, \mathrm{sd}=0.67)$, vertigo $(M=1.56$, $\mathrm{sd}=0.65)$, headache $(M=1.69, \mathrm{sd}=0.66)$, nausea $(M=1.19$, $\mathrm{sd}=0.43)$, cardiovascular problems $(M=1.44$, sd $=0.60)$.

Furthermore, Kussel (2018) states that adaptation behaviour is a response to heat stress experienced. While heat stress can be determined by various factors, in this study, SHS will be included, meaning the perceived degree of stress caused by a heatwave at home. This was included in the questionnaire by asking about the SHS level at home (by day and night) on a 5-point Likert scale. Alternatively, the participants could answer 'I don't know' if they were not able to judge the level of SHS, for example, because they rarely experienced this situation. An overview of SHS is given in

Table 6 Overview of mean indoor temperatures as recorded by temperature data loggers 24 to 26 July 2019.

\begin{tabular}{llc} 
M Temperature & $\boldsymbol{n}$ & $\%$ \\
\hline Below $24^{\circ} \mathrm{C}$ & 8 & 1.9 \\
$24-25^{\circ} \mathrm{C}$ & 26 & 6 \\
$25-26^{\circ} \mathrm{C}$ & 67 & 15.5 \\
$26-27^{\circ} \mathrm{C}$ & 103 & 23.9 \\
$27-28^{\circ} \mathrm{C}$ & 106 & 24.6 \\
Above $28^{\circ} \mathrm{C}$ & 118 & 27.4 \\
\hline$M$ mean. & & \\
\hline
\end{tabular}

Table 5 Statements included in knowledge about heat risks construct.

\begin{tabular}{|c|c|c|c|}
\hline Item no. & Statement & $n$ right & $\%$ \\
\hline 1 & Older and very young people are particularly vulnerable during a heat wave. & 412 & 95.6 \\
\hline 2 & Excessive sweating during a heat wave may be a sign of heat stress. & 244 & 56.6 \\
\hline 3 & People with a cardiac disease are in danger of becoming sick during a heat wave. & 355 & 82.4 \\
\hline 4 & Heat-related diseases can lead to death. & 362 & 84.0 \\
\hline 5 & There is no such evidence for heat waves to cause respiratory diseases. & 101 & 23.4 \\
\hline 6 & Diabetes is an example for a heat-related disease. & 295 & 68.4 \\
\hline 7 & Heat waves foster the development of harmful bacteria in water and food. & 392 & 91.0 \\
\hline 8 & Heat waves can be a factor for depression and anxiety. & 108 & 25.1 \\
\hline 9 & Due to the building's shade, heat waves are less common in cities than in rural areas. & 368 & 85.4 \\
\hline 10 & Heat stress during night time is worse than heat stress during daytime. & 183 & 42.5 \\
\hline
\end{tabular}




\begin{tabular}{|lllll}
\hline Table 7 Subjective heat stress item and statistics. & & \\
Item: How do you rate your personal heat stress & $\boldsymbol{n}$ & $\boldsymbol{M}$ & sd \\
perception in the following situation... & & & \\
\hline ... at home during the day & & 2.71 & 1.11 \\
Very high & 31 & & \\
High & 57 & & \\
Neutral & 139 & & \\
Low & 121 & & \\
Very low & 57 & & \\
No answer & 26 & & \\
$\ldots$ at home during the night & & 3.2 & 1.16 \\
Very high & 64 & & \\
High & 105 & & \\
Neutral & 148 & & \\
Low & 72 & & \\
Very low & 38 & & \\
No answer & 6 & & \\
\hline M mean, sd standard deviation. & & & \\
Cronbach's $\alpha=0.71$. & & & \\
\hline
\end{tabular}

Table 7. This variable will be included in the hierarchical regression model in the analysis section.

In his study, Kussel (2018) states that an increase of mean indoor temperature by one degree celsius during summer is related to a $2.3 \%$ higher probability of adaptation while WhiteNewsome et al. (2012) found that indoor temperature is significantly related to adaptive behaviour. Even though the indoor temperature will be included in the hypotheses that will be introduced in the next section, according to the PADM, indoor temperatures are supposed to have an indirect influence via heat risk perception. To examine their direct influences, indoor temperatures (INT) will be included in the later analysis as a direct influence as well.

Hypotheses. In this study the PADM is being applied to heat adaptation behaviour among citizens of the city of Augsburg, Germany. Heat adaptation behaviour is essential for (vulnerable) people during the summer months to protect themselves against health impairments during severe heat waves. The research model is shown in Fig. 1.

Next to efficacy-related and resource-related variables, the PADM assumes that adaptation behaviour depends on heat risk perception, whereas the perceived heat risk is related to the indoor temperatures during heat waves and the demographic characteristics of the participants. These two factors are thought to influence the hazard adjustment attributes as well.

Other studies using the PMT showed that threat and a coping appraisal are related to climate change adaptation behaviour (Goli et al., 2020). The PADM predicts efficacy-related and RRA influencing adaptation behaviour. The first hypotheses therefore are:

H1a: The efficacy-related attribute is positively related to heat adaptation behaviour.

H1b: The resource-related attributes are positively related to heat adaptation behaviour.

In their research, Lindell and Hwang (2008) showed that risk perception depends on the risk area a person lives in. Akerlof et al. (2015) found that being located in an area exposed to risk (of flooding) is related to higher risk perception. For heat as the risk in this paper, the risk area means the extent of exposure a person has to face, hence if the indoor temperature is high during a heat wave. Therefore, the following hypotheses are deducted:

$\mathrm{H} 2 \mathrm{a}$ : The indoor temperature during a heat wave is related to the efficacy-related attribute and knowledge.

$\mathrm{H} 2 \mathrm{~b}$ : Indoor temperature during a heat wave is related to heat risk perception.

Esplin et al. (2019) found that risk perception influences selfreported protection behaviour. People that perceive heat as an actual risk are more likely to take adaptation measures that are meant to protect their health from consequences of heat exposure. In their study, Arbuckle et al. (2015) presented findings of farmers who are more willing to take adaptation measures when their perceived risk towards heat waves is higher. Other studies report similar results (Kim et al., 2014; Liu et al., 2013; Wolf et al., 2010). Therefore, the following hypothesis can be deducted:

H3: Heat risk perception is a significant predictor of heat adaptation behaviour.

Beckmann and Hiete (2020) found that young age is one of the predictors of heat risk perception, Akompab et al. (2013) additionally found that a higher income as well as being married were significant predictors of climate change risk perception. Other studies claim that females perceive higher climate change risks or are more likely to take adaptation measures (Esplin et al., 2019; Khare et al., 2015; Kim et al., 2014; Semenza et al., 2008). Therefore, the demographic characteristics included in this study are: age, living alone and gender and the hypothesis deducted is

H4: Demographic characteristics (age, gender, living alone) are significantly related to heat risk perception.

The items included in the questionnaire to test the hypotheses are listed in Table 8.

\section{Analyses and results}

To give an overview over participants in this study, descriptive statistics are presented in the following section. Afterwards, regression analyses were performed to test the previously introduced hypotheses.

Descriptive statistics. Table 9 shows descriptive statistics of the participants and their heat adaptation behaviour. $15.5 \%$ of the participants are 65 years old and older, $60.6 \%$ are female and $58.9 \%$ hold a university degree. Most of the participants reported a monthly household income of $1000-2000 €(21.6 \%)$ and of $2000-3000 €(20.6 \%)$. Of the 431 participants, $154(35.7 \%)$ were living alone and $121(28.1 \%)$ live in a house or apartment that they own themselves.

Table 10 shows Pearson correlation of all introduced variables. Regarding heat adaptation behaviour $(\mathrm{HAB})$ there is a moderate correlation with age (negative), SHS and the HIS. Weak correlation can be found with knowledge, heat risk perception and living alone (negative) and the indoor temperature. These correlations will be analysed further in the following sections and the hierarchical regression model.

Results of hypotheses testing. The hypotheses were tested using different statistical tests. Effect sizes in this section are reported as $f$ and interpreted following Cohen (1988). To test Hypothesis 1a ('The efficacy-related attribute is positively related to heat adaptation behaviour'), a one-way ANOVA was conducted. The ERA was measured on a 5-point Likert scale from 1 (totally disagree) to 5 (totally agree). Data is normally distributed for each group 
Table 8 Overview of variables and constructs used for hypotheses testing.

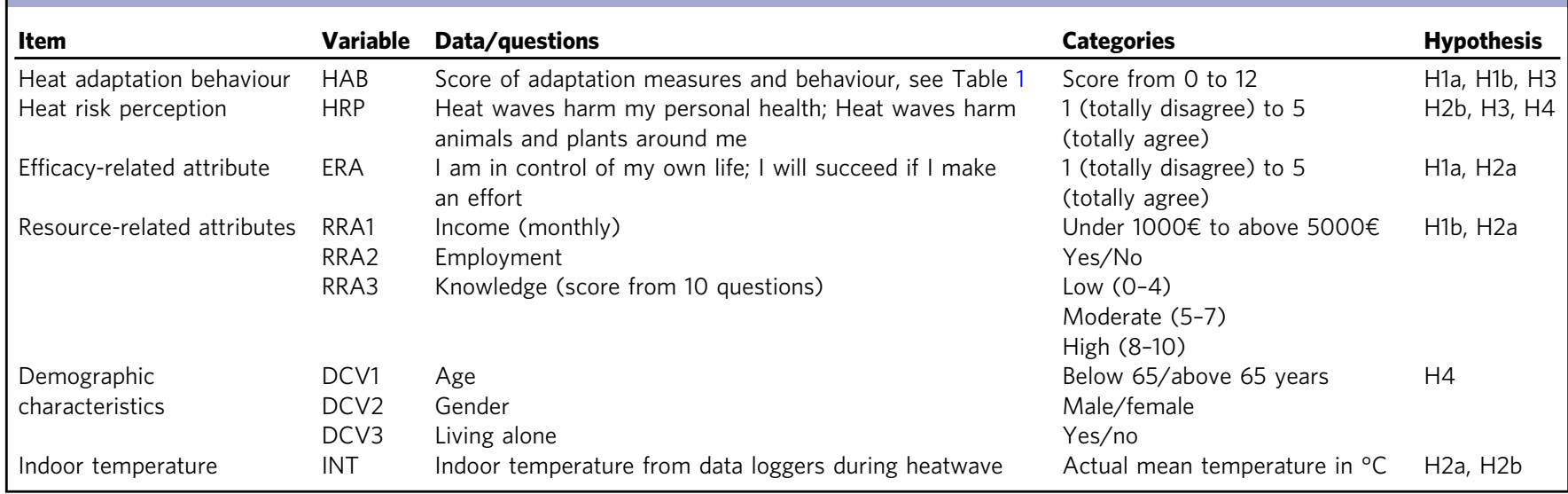

Table 9 Descriptive statistics of data sample $(N=431)$ and heat adaptation behaviour.

\begin{tabular}{lllll} 
& $\boldsymbol{n}$ & \% & M HAB & sd \\
\hline Age (DCV1) & & & & \\
Under 65 years & 364 & 84.5 & 6.34 & 1.62 \\
65 years and older & 67 & 15.5 & 5.1 & 1.52 \\
Gender (DCV2) & & & & \\
Male & 169 & 39.2 & 6.07 & 1.73 \\
Female & 262 & 60.6 & 6.19 & 1.62 \\
Living alone (DCV3) & & & & \\
Yes & 154 & 35.7 & 5.92 & 1.7 \\
No & 277 & 64.3 & 6.14 & 1.64 \\
Income (RRA1) & & & & \\
Under 1000€ & 36 & 8.4 & 5.97 & 1.81 \\
1000-2000€ & 91 & 21.1 & 6.15 & 1.63 \\
2000-3000€ & 89 & 20.6 & 6.22 & 1.6 \\
3000-4000€ & 62 & 14.4 & 6.19 & 1.72 \\
4000€ and above & 71 & 16.5 & 6.18 & 1.5 \\
No answer & 82 & 19 & & \\
Employment (RRA2) & & & & \\
Yes & 312 & 72.4 & 6.22 & 1.65 \\
No & 119 & 27.6 & 5.95 & 1.69 \\
Knowledge (RRA3) & & & & \\
Low (0-4) & 41 & 9.5 & 5.83 & 1.84 \\
Moderate (5-7) & 268 & 62.2 & 6.02 & 1.68 \\
High (8-10) & 122 & 28.3 & 6.52 & 1.52 \\
\hline M mean, sd standard deviation, HAB heat adaptation behaviour. & & \\
\hline
\end{tabular}

(Shapiro-Wilk test, $p>0.05$ ) and there is the homogeneity of variance (Levene's test, $p>0.05$ ). However, there is no statistically significant result between the ERA and the HAB variables $(p>0.05)$. Hypothesis la could therefore not be supported.

The same results were found for hypothesis $1 \mathrm{~b}$ ('The RRA are positively related with heat adaptation behaviour') with the factors income and employment. Both ANOVAs did not show any significance. However, the heat adaptation behaviour differed significantly for the different groups of knowledge levels, $F(2$, $462)=4880, p=0.008, f=0.21$. Tukey post-hoc analysis revealed a significant difference $(p<0.001)$ between heat adaptation behaviour of the group with highest knowledge with the groups of low or moderate knowledge. Mean level of heat adaptation behaviour slightly decreased from high to low knowledge $(-0.69$, $95 \%-\mathrm{CI}[-1.36,-0.03])$, and from high to moderate knowledge $(-0.48,95 \%-\mathrm{CI}[-0.88,-0.07])$. Hypothesis $1 \mathrm{~b}$ could therefore be supported for knowledge as the independent variable.
To test hypothesis $2 \mathrm{a}$ ('The indoor temperature during a heat wave is related to the efficacy-related attribute and knowledge'), two linear regression analyses were conducted to analyse the relationship between indoor temperature on self-efficacy and knowledge. However, both regression models did not show statistically significant results. Therefore, hypothesis 2 a could not be supported.

A linear regression analysis was conducted to test the relation of indoor temperature and heat risk perception according to hypothesis $2 \mathrm{~b}$ ('Indoor temperature during a heatwave is related to heat risk perception'). The regression did not show significant results $(p=0.147)$. Hypothesis $2 \mathrm{~b}$ could not be supported.

One-way ANOVA was conducted to test hypothesis 3 ('Heat risk perception is a significant predictor of heat adaptation behaviour'). Data is normally distributed for each group (Shapiro-Wilk test, $p>0.05$ ) and there is the homogeneity of variance (Levene's test, $p>0.05$ ). HAB differed statistically significantly for the different HRP groups, $F(6,458)=3084$, $p<0.001, f=0.2$. Mean level of heat adaptation behaviour slightly increased from low (value of 1.5) to high (value of 4) HRP (0.98, $95 \% \mathrm{CI}[0.13,1.84])$, and from low (value of 2 ) to high (value of 4 ) $\operatorname{HRP}(0.84,95 \%$ CI $[0.018,1.66])$. Hypothesis 3 could therefore be supported.

T-tests were used to test hypothesis 4 ('Demographic characteristics are significantly related to heat risk perception'). First, the test was conducted with the two age groups (DCV1) to assess the effects of DCV1 on HRP. There was a significant difference with the younger age group showing higher HRP than the older age group, $t(93.417)=2.839, p=0.006, f=0.14$. The tests for the factors gender (DCV2) and living alone (DCV3) showed no significant results. Hypothesis 4 could therefore be supported for age as influencing factor.

Results of hierarchical regression model. The testing of the hypotheses showed that hypothesis $1 \mathrm{~b}$ could be supported for knowledge as the influencing factor, hypothesis $2 \mathrm{~b}$ and 3 could be supported, as well as hypothesis 4 for age as further influencing factor. However, as indicated in the section 'Other influencing factors' and from Table 6 with the correlations of all variables, it is known that SHS and health implications do have an effect on heat adaptation behaviour.

Therefore, a hierarchical regression analysis was conducted as shown in Table 7 . In step 1 , the model implies that HRP is a significant indicator for heat adaptation behaviour $(\beta=0.142$; $p=0.013$ ) which corresponds to the earlier supported hypothesis 3 . The other variables in the model step 1 showed no statistical significance, which aligns with the rejected hypotheses $1 \mathrm{a}$ and $1 \mathrm{~b}$. 


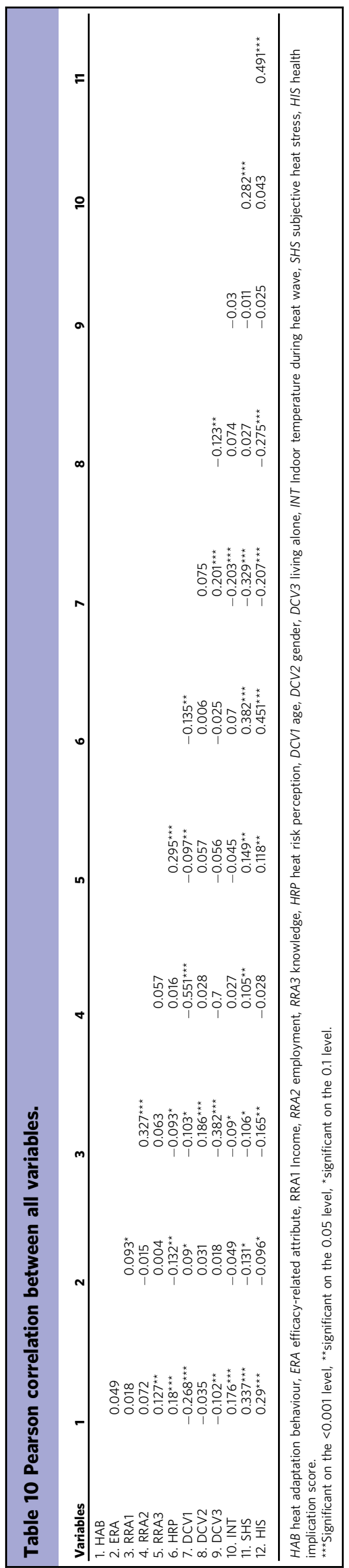

In Table 7 , step 2 of the model $\left(R^{2}=0.164\right)$, where all variables included in the PADM were added to the model, ERA becomes a significant factor $(\beta=0.102 ; p=0.05)$. However, the coefficient was smaller than the coefficients of the other two significant variables in this model, which were the age groups (DCV1; $\beta=-0.284, p<0.001)$ and the mean indoor temperature during a heatwave $(\beta=0.187 ; p=0.001)$. This shows a direct influence of age and indoor temperature on $\mathrm{HAB}$, which has not been tested because in the PADM model there were no direct relations between these variables. In step 3 of the model (adjusted $\left.R^{2}=0.217\right)$, additionally to self-efficacy $(\beta=0.116 ; p=0.023)$, age (DCV1) $(\beta=-0.209 ; p=0.001)$ and indoor temperature $(\beta=0.156 ; p=0.004)$, SHS at home and the HIS became significant indicators for heat adaptation behaviour with $\beta=0.157 ; p=0.014$ for SHS and $\beta=0.164 ; p=0.012$ for HIS.

Figure 1, showing the initial PADM for heat adaptation behaviour in Augsburg, Germany, has been adjusted according to the regression model in Table 11. Figure 2 shows the adjusted model with the arrows indicating significant relations and the two added variables SHS at home and health implications during heat waves as additional indicators.

Even though knowledge did not show significance in step 3 of the regression model, hypothesis $1 \mathrm{~b}$ was supported for knowledge as the indicator. Therefore, in the adjusted protective action decision model, influencing indicators for heat adaptation behaviour are: knowledge, self-efficacy, heat risk perception, indoor temperature, age, health implications and SHS at home.

\section{Discussion and limitations}

Contrary to the hypothesized association of the ERA, as well as time and income (RRA1 and RRA2) with heat adaptation behaviour, the results did not support hypotheses $1 \mathrm{a}$ and $1 \mathrm{~b}$ (in parts). This must be seen as a good message for heat adaptation management: low self-efficacy, low income and lack of time are (statistically) no hurdles for taking adaptation measures in this study.

The results of the applied PADM supported hypothesis $1 \mathrm{~b}$ regarding the relation of knowledge and heat adaptation behaviour, hypothesis 3 showing the influence of heat risk perception on heat adaptation behaviour and hypothesis 4 regarding the influence of age on heat risk perception. These results align with previous research introduced earlier in this paper. Especially the relation between HRP and $\mathrm{HAB}$ was found in studies before (Esplin et al., 2019; Arbuckle et al., 2015; Kim et al., 2014; Wolf et al., 2010; Liu et al., 2013). This underlines the importance of risk perception research in combination with climate change adaptation behaviour. As knowledge is significantly related to $\mathrm{HAB}$, it is important to know that education among households is influencing a person's adaptation behaviour significantly.

However, it is important to stress, that indoor temperatures during heatwave did not show significant influence on HRP in the hypotheses tests contrarily to what was expected from the theoretical model and included in $\mathrm{H} 2 \mathrm{a}$ and $\mathrm{H} 2 \mathrm{~b}$. Therefore, results differ from Lindell and Hwang (2008) and Akerlof et al. (2015) and this could imply that indoor temperatures are not a reliable measure for a characteristic risk area a person is in when it comes to the relation to heat risk perception.

Regarding hypothesis 4, demographic characteristics (age, gender, living alone) being related to heat risk perception, only age was significant. This was an unexpected result since gender and living alone were identified as influencing factors in Akompab et al. (2013), Esplin et al. (2019), Khare et al. (2015), Kim et al. (2014) and Semenza et al. (2008). One reason could be the different countries the studies were conducted in and the different cultures of the participants. People living alone might have 
Table 11 Hierarchical regression analysis of heat adaptation behaviour.

\begin{tabular}{|c|c|c|c|c|c|c|c|c|c|}
\hline \multirow[t]{2}{*}{ Variable } & \multicolumn{3}{|c|}{ Step1; $R^{2}=0.194 ;$ Adj. $R^{2}=0.038$} & \multicolumn{3}{|c|}{ Step2; $R^{2}=0.405 ;$ Adj. $R^{2}=0.164$} & \multicolumn{3}{|c|}{ Step3; $R^{2}=0.466 ;$ Adj. $R^{2}=0.217$} \\
\hline & $\beta$ & Std. $\beta$ & VIF & $\beta$ & Std. $\beta$ & VIF & $\beta$ & Std. $\beta$ & VIF \\
\hline ERA & 0.108 & 0.084 & 1.026 & 0.131 & $0.102^{\star}$ & 1.036 & 0.148 & $0.116^{\star}$ & 1.039 \\
\hline RRA1 & -0.021 & -0.039 & 1.138 & -0.015 & -0.027 & 1.420 & 0.000 & 0.01 & 1.436 \\
\hline RRA2 & 0.290 & 0.084 & 1.118 & -0.268 & -0.075 & 1.585 & -0.174 & -0.048 & 1.603 \\
\hline RRA3 & 0.061 & 0.060 & 1.084 & 0.066 & 0.065 & 1.091 & 0.055 & 0.054 & 1.094 \\
\hline HRP & 0.284 & $0.142^{\star}$ & 1.106 & 0.185 & 0.093 & 1.133 & -0.019 & -0.009 & 1.341 \\
\hline DCV1 & & & & -1.287 & $-0.284^{\star \star}$ & 1.566 & -0.948 & $-0.209^{\star \star}$ & 1.677 \\
\hline DCV2 & & & & -0.066 & -0.020 & 1.088 & 0.038 & 0.012 & 1.220 \\
\hline DCV3 & & & & -0.226 & -0.068 & 1.277 & -0.216 & -0.065 & 1.285 \\
\hline INT & & & & 0.191 & $0.187^{\star \star}$ & 1.093 & 0.158 & $0.156^{\star}$ & 1.169 \\
\hline SHS & & & & & & & 0.249 & $0.157^{\star \star}$ & 1.645 \\
\hline HIS & & & & & & & 0.088 & $0.164^{\star}$ & 1.711 \\
\hline
\end{tabular}

Step 1: variables that have initially been directly linked with HAB in the PADM; Step 2: all variables that have initially been included in the PADM; Step 3: All available variables that have been introduced and found as being influencing in the literature.

Std. $\beta$ standardized $\beta$, VIF variance influence factor.

${ }^{\star}$ Significant on 0.05 level, ${ }^{\star \star}$ significant on 0.001 level.

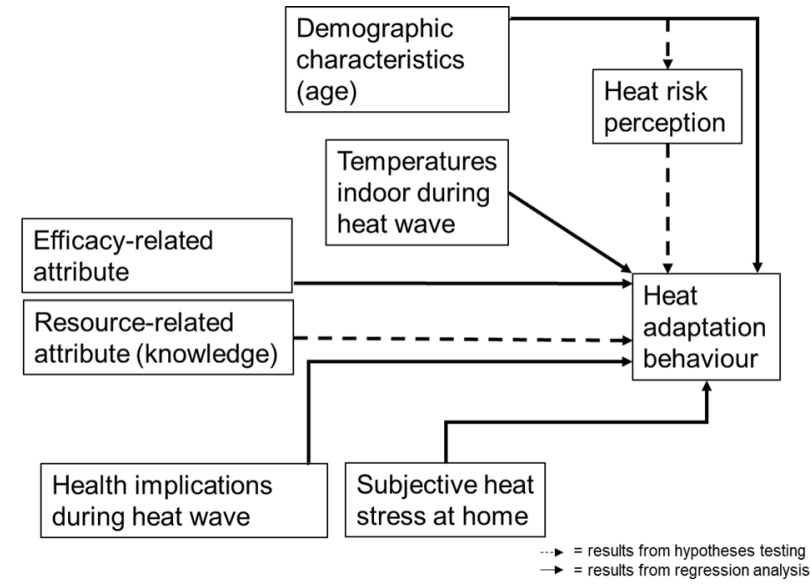

Fig. 2 Adjusted PADM for heat adaptation behaviour in this study. Figure shows flow of inormation in the adjusted PADM for this study. Boxes show variables, arrows show results from regression analysis and dotted arrows show results from hypotheses testing.

enough social interaction with people not living in the same household in this study. For the households in Augsburg this means, when communicating about heat risks and heat adaptation advantages, the audience has to be differentiated by age rather than by gender or living situation, which makes the information spreading for government institutions easier to allocate.

After testing hypotheses, hierarchical regression analysis was conducted to include further variables which were identified as relevant in the literature. Step 3 of the model shows a significant influence of the ERA on heat adaptation behaviour, in agreement with the theory of the PADM. People who think their life rather depends on fate, accident or other people that take decisions for them, rather tend to not take adaptation measures. Taken into practice, this might be a problem when adaptation measures should be fostered because counteracting against an external LOC is challenging to handle as it is an intrinsic convincement.

Furthermore, age shows a negative effect, meaning younger people rather tend to adapt to heat which has already been introduced for hypothesis 4 that was supported in this study.

In step 3, the indoor temperature during heatwave showed a significant effect, which aligns with Kussel (2018) and WhiteNewson et al. (2012). It is important to stress that in this study as well as in the literature higher indoor temperature during a heatwave leads to a higher probability of taking adaptation measures. This leaves advice to authorities and governmental institutions that to some extent, households tend to adapt to rising temperatures autonomously.

The same applies to the further significant factor, SHS. This implies that the higher a person reported his or her SHS level at home, the higher the probability that he or she takes adaptation measures at home. Furthermore, similarly to Esplin et al. (2019) and Kim et al. (2014), the health implications of the participants were a significant factor for heat adaptation behaviour. These factors contribute in some kind to a self-balancing system of adaptation in private households.

In the hierarchical regression model, the RRA, as well as gender and living alone do not show significant effects. Surprisingly, in step 3 of the model, heat risk perception is not a significant factor either. However, as hypothesis 3 was supported, it should still be taken into account and seen as relevant for further research.

For practitioners developing heat action plans, all these factors help to decide on the content of such plans. The introduced variables should be paid attention to as indicators for action thresholds. This helps to prevent health consequences caused by heat that can lead to higher mortality. This information can be included in municipal heat action plans but also in community groups taking care of each other. It is also valuable for institutions like retirement homes or home care nursing services.

In the end, this study suggested an adjusted version of the PADM according to the results of the hierarchical regression analysis. It is important to note, that the number of cases in the data set is admittedly sufficient for this study, however, it is not necessarily representative of (German) cities in general. Limitations also include a possible bias of participants of the study who signed up voluntarily and might already have been more sensitized to heat risks due to higher bedroom temperature, education, health profiles, etc. A possible bias could have been caused by the nature of taking a survey online, as this happened over the entire month of July, it is not safe to say that every participant was exposed to the same temperature while taking the survey. Also, because the survey was taken in German and some constructs were taken from studies published in English, they have not been tested in a pilot study beforehand. This leaves room for further research to conduct pilot studies with heat adaptation-related constructs in various languages. Therefore, and to better understand heat adaptation behaviour in German cities, it is recommended to replicate this study in other cities in Germany and 
elsewhere. Finally, as studies have shown, family members do not always agree with each other when it comes to climate change response (Head et al., 2016), behaviour or consumption decisions (Grønhøj, 2006) or preparation for extreme weather events (Hung, 2018). Therefore, it has to be kept in mind that even though the current study refers to household behaviour, it is rather the behaviour of the household member answering the survey questions.

Further limitations may arise from the fact that the calculated values of Cronbach's alpha ( 0.66 for heat risk perception, 0.6 for ERAs, 0.45 for knowledge about heat risks and 0.71 for SHS) are slightly to considerably lower than the level of 0.7 often considered in the literature as "desired or adequate" (cf. Schmitt, 1996). Cronbach's alpha measures whether items within the instrument (or construct) correlate well with at least some other items in the instrument (Gardner, 1995) and thus indicates average interrelatedness of the items in the sample (Schmitt, 1996). Note that a high Cronbach's alpha does not necessarily indicate homogeneity or unidimensionality (cf. Gardner, 1995; Tan, 2009) and that Cronbach's alpha "cannot be seen as a measure of a scale or instrument per se but only of its application to a particular sample of respondents" (Taber, 2018). For a homogenous or unidimensional instrument all items selected to describe that instrument are required to highly correlate with the instrument and thus also which each other. In such a case, a very high Cronbach's alpha value suggests that some items are redundant (Tavakol and Dennick, 2011) and a low value would be indicative of a large measurement error in the test. That's why Cronbach's alpha has high relevance for affective instruments for which "instrument designers (or adaptors) do need to demonstrate that items on a single scale are indeed measuring the same thing" (Taber, 2018). However, for cognitive instruments "testing a range of distinct knowledge facets should not be expected to give high alphas" (Taber, 2018). Berger and Hänze (2015) (also cited in Taber, 2018) consequently regard a Cronbach's alpha value of 0.45 in a pre-test and of 0.60 in the post-test for a knowledge test measuring different physics concepts as acceptable. Though we cannot exclude that high measurement errors have resulted in the low Cronbach's alpha value of 0.45 for the knowledge about heat risks construct in our study, we argue that the bandwidth of knowledge covered in the construct is the main reason. We interpret the rather low correlation values between the items (not shown) by still insufficient and fragmented knowledge about heat risks in the population. With fragmented, we meant that most people have some knowledge but what they know is highly variable. Anyway, a pre-test was not conducted in this study and therefore, it is highly recommended for future research to further investigate the knowledge construct and test its reliability in pre- and post-tests with different groups of respondents. The first step to do so might be to conduct expert interviews. In the final steps, different reliability indicators might have to be tested to assure satisfactory results.

\section{Conclusion}

In the future, heat waves will occur more frequently and with higher intensity. An elevated excess number of deaths caused by heat can be observed already today (Watts et al., 2020). Rising temperatures and urbanization challenge cities and communities with regard to health implications caused by extreme heat exposure. Therefore, studies investigating heat adaptation behaviour are necessary to give insight into the complex constructs of adaptation in private households and its influencing factors. This study identified key factors influencing adaptation behaviour towards heat risks. Unlike other studies, this research applied the PADM model and included more variation of investigated factors. The background section additionally shed light on already established theoretical frameworks for the field of climate adaptation behaviour and introduced the PADM in more detail. Additionally to its theoretical implications, this study showed some implications on the practical side.

Adaptation behaviour in households in Augsburg neither depends on a high income nor on a time budget. This is an important fact as it means that not only do people with solvent households tend to take adaptation measures and should therefore be aimed to receive adequate information but the information should be spread throughout all households regarding income situation.

It is also worth noting, that people (subjectively) affected by heatwaves tend to take adaptation measures themselves. That is shown by mean indoor temperature and SHS which are significant factors for heat adaptation behaviour. Furthermore, health implications suffered during a heatwave is an indicator as well which means that people experiencing consequences on their health caused by heat rather take adaptation measures to protect themselves.

Since age and knowledge were identified as significant factors, however, it is necessary to inform older people directly about heat risks. Not only could that lead to a higher risk perception but directly to more adaptation measures taken and therefore to a reduction in health issues caused by exposure during a heatwave. However, the knowledge construct should be re-developed and tested again to assure adequate reliability within the instrument.

The PADM is not only an adequate model to investigate climate change adaptation behaviour but also heat adaptation behaviour specifically. It combines relevant factors appropriately to gain an understanding of their relations. Even though the model has been slightly adapted for this study, in the end, it is recommended to further examine heat adaptation behaviour.

\section{Data availability}

The datasets generated and analysed during the current study are not publicly available due to further publications in process but are available from the corresponding author on request.

Received: 2 March 2021; Accepted: 21 September 2021; Published online: 12 October 2021

\section{References}

Ajzen I (1991) The Theory of Planned Behaviour. Organ Behav Hum Decision Process 50:179-211

Akerlof KL, Delamater PL, Boules CR, Upperman CR, Mitchell CS (2015) Vulnerable populations perceive their health as at risk from climate change. Int J Environ Res Public Health 12(12):15419-15433. https://doi.org/10.3390/ ijerph121214994

Akompab DA, Bi P, Williams S, Grant J, Walker IA, Augoustinos M (2012) Awareness of and attitudes towards heat waves within the context of climate change among a cohort of residents in Adelaide, Australia. Int J Environ Res Public Health 10(1):1-17. https://doi.org/10.3390/ijerph10010001

Akompab DA, Bi P, Williams S, Grant J, Walker IA, Augoustinos M (2013) Heat waves and climate change: applying the health belief model to identify predictors of risk perception and adaptive behaviours in Adelaide, Australia. Int J Environ Res Public Health 10(6):2164-2184. https://doi.org/10.3390/ ijerph 10062164

Alcoforado MJ, Marques D, Garcia RAC, Canário P, Nunes MDEF, Nogueira H, Cravosa A (2015) Weather and climate versus mortality in Lisbon (Portugal) since the 19 century. Appl Geogr 57:133-141. https://doi.org/10.1016/ j.apgeog.2014.12.017

Arbuckle JG, Morton LW, Hobbs J (2015) Understanding farmer perspectives on climate change adaptation and mitigation: the roles of trust in sources of climate information, climate change beliefs, and perceived risk. Environ Behav 47(2):205-234. https://doi.org/10.1177/0013916513503832 
Arunrat N, Wang C, Pumijumnong N, Sereenonchai S, Cai W (2017) Farmers' intention and decision to adapt to climate change: a case study in the Yom and Nan basins, Phichit province of Thailand. J Clean Prod 143:672-685. https://doi.org/10.1016/j.jclepro.2016.12.058

Bamberg S, Möser G (2007) Twenty years after Hines, Hungerford, and Tomera: a new meta-analysis of psycho-social determinants of pro-environmental behaviour. J Environ Psychol 27(1):14-25. https://doi.org/10.1016/ j.jenvp.2006.12.002

Berger R, Hänze M (2015) Impact of expert teaching quality on novice academic performance in the jigsaw cooperative learning method. Int J Sci Educ 37(2):294-320. https://doi.org/10.1080/09500693.2014.985757

Beck C, Straub A, Breitner S, Cyrys J, Philipp A, Rathmann J et al. (2018) Air temperature characteristics of local climate zones in the Augsburg urban area (Bavaria, southern Germany) under varying synoptic conditions. Urban Clim 25:152-166. https://doi.org/10.1016/j.uclim.2018.04.007

Beckmann SK, Hiete M (2020) Predictors associated with health-related heat risk perception of urban citizens in Germany. Int J Environ Res Public Health 17(3):1-11. https://doi.org/10.3390/ijerph17030874

Beckmann SK, Hiete M, Beck C (2021) Threshold temperatures for subjective heat stress in urban apartments-analysing nocturnal bedroom temperatures during a heat wave in Germany. Clim Risk Manag 32:100286. https://doi.org/ 10.1016/j.crm.2021.100286

Birkmann J, von Teichman K (2010) Integrating disaster risk reduction and climate change adaptation: key challenges_-scales, knowledge, and norms. Sustain Sci 5(2):171-184. https://doi.org/10.1007/s11625-010-0108-y

Budhathoki NK, Paton D, Lassa JA, Bhatta GD, Zander KK (2020) Heat, cold, and floods: exploring farmers' motivations to adapt to extreme weather events in the Terai region of Nepal. Nat Hazards 103(3):3213-3237. https://doi.org/ 10.1007/s11069-020-04127-0

Bunz M, Mücke H-G (2017) Klimawandel-physische und psychische Folgen. Bundesgesundheitsbl Gesundheitsforsch Gesundheitsschutz 60(6):632-639. https://doi.org/10.1007/s00103-017-2548-3

Çakır Yıldırım B, Karaarslan Semiz G (2019) Future teachers' sustainable water consumption behavior: a test of the value-beliefnorm theory. Sustainability 11(6):1558. https://doi.org/10.3390/su11061558

Campbell S, Remenyi TA, White CJ, Johnston FH (2018) Heatwave and health impact research: a global review. Health Place 53:210-218. https://doi.org/ 10.1016/j.healthplace.2018.08.017

Chen M-F (2016) Extending the theory of planned behavior model to explain people's energy savings and carbon reduction behavioral intentions to mitigate climate change in Taiwan-moral obligation matters. J Clean Prod 112:1746-1753. https://doi.org/10.1016/j.jclepro.2015.07.043

Cohen J (1988) Statistical power analysis for the behavioral sciences, 2nd edn. Laurence Erlbaum Associates, Publishers. Deutscher Wetterdienst (2019) Climate Data Center. https://cdc.dwd.de/portal/, updated on 12/ $3 / 2019$, checked on $3 / 17 / 2020$.

Deutscher Wetterdienst (2020) Vieljährige Mittelwerte. https://www.dwd.de/DE/ leistungen/klimadatendeutschland/vielj_mittelwerte.html, updated on 3/17/ 2020 , checked on $3 / 17 / 2020$.

Elitech (2020) RC-5 USB temperature data logger operation instruction. https:// www.elitech.uk.com/uploads/soft/manual2017/RC-5.pdf, checked on 9/16/ 2020.

Esplin ED, Marlon JR, Leiserowitz A, Howe PD (2019) "Can you take the heat?" Heat-induced health symptoms are associated with protective behaviors. Weather Clim Soc 11(2):401-417. https://doi.org/10.1175/WCAS-D-180035.1

Gardner PL (1995) Measuring attitudes to science: unidimensionality and internal consistency revisited. Res Sci Educ 25(3):283-289

Goli I, Omidi Najafabadi M, Lashgarara F (2020) Where are we standing and where should we be going? Gender and climate change adaptation behavior. J Agric Environ Eth 33(2):187-218. https://doi.org/10.1007/s10806-020-09822-3

Grønhøj A (2006) Communication about consumption: a family process perspective on 'green' consumer practices. Journal of Consumer Behaviour 5(6):491-503. https://doi.org/10.1002/cb.198

Head L, Gibson C, Gill N, Carr C, Waitt G (2016) A meta-ethnography to synthesise household cultural research for climate change response. Local Environment. 21(12):1467-1481. https://doi.org/10.1080/13549839.2016.1139560

Hengst-Ehrhart Y (2019) Knowing is not enough: exploring the missing link between climate change knowledge and action of German forest owners and managers. Ann Forest Sci 76(4). https://doi.org/10.1007/s13595-019-0878-z

Hung LS (2018) Gender, Intra-Household Dynamics, and Household Hurricane Preparedness: An Exploratory Study Employing a Dyadic Interview Approach. Int J Disaster Risk Sci 9(1):16-27. https://doi.org/10.1007/s13753018-0158-9

IPCC (2019) IPCC special report on climate change, desertification, land degradation, sustainable land management, food security, and greenhouse gas fluxes in terrestrial ecosystems. https://www.ipcc.ch/site/assets/uploads/2019/ 08/Fullreport-1.pdf, checked on 11/12/2019.
Kalkstein AJ, Sheridan SC (2007) The social impacts of the heat-health watch/ warning system in Phoenix, Arizona: assessing the perceived risk and response of the public. Int J Biometeorol 52(1):43-55. https://doi.org/ 10.1007/s00484-006-0073-4

Khare S, Hajat S, Kovats S, Lefevre CE, de Bruin WB, Dessai S, Bone A (2015) Heat protection behaviour in the UK: results of an online survey after the 2013 heatwave. BMC Public Health 15:878. https://doi.org/10.1186/s12889-0152181-8

Kim M, Kim H, You M (2014) The role of public awareness in health-protective behaviours to reduce heat wave risk. Met Apps 21(4):867-872. https:// doi.org/10.1002/met.1422

Kim S, Shin W (2017) Understanding American and Korean Students' Support for Pro-environmental Tax Policy: the application of the value-belief-norm theory of environmentalism. Environ Commun 11(3):311-331. https:// doi.org/10.1080/17524032.2015.1088458

Klinenberg E (2015) Heat wave: a social autopsy of disaster in Chicago. University of Chicago Press

Kovaleva A, Beierlein C, Kemper CJ, Rammstedt B (2014) Internale-ExternaleKontrollüberzeugung-4 (IE-4). Zusammenstellung sozialwissenschaftlicher Items und Skalen (ZIS). https://doi.org/10.6102/ZIS184

Kussel G (2018) Adaptation to climate variability: evidence for German households. Ecol Econ 143:1-9. https://doi.org/10.1016/j.ecolecon.2017.06.039

Leibniz-Institut für Sozialwissenschaften (2021) Gesis: Die Zusammenstellung Sozialwissenschaftlicher Items und Skalen. https://zis.gesis.org/, checked on 2/17/2021.

Levenson H (1973) Distinctions within the concept of internal-external control: development of a new scale. In: Proceedings of the 80th annual convention of the APA Published: Washington, American Psychological Association (APA) (7). pp. 261-262.

Lindell MK, Hwang SN (2008) Households' perceived personal risk and responses in a multihazard environment. Risk Anal 28(2):539-556. https://doi.org/ 10.1111/j.1539-6924.2008.01032.x

Lindell MK, Perry RW (1992) Behavioral foundations of community emergency planning. Hemisphere Publishing Corp.

Lindell MK, Perry RW (2012) The protective action decision model: theoretical modifications and additional evidence. Risk Anal 32(4):616-632. https:// doi.org/10.1111/j.1539-6924.2011.01647.x

Liu T, Xu YJ, Zhang YH, Yan QH, Song XL, Xie HY et al. (2013) Associations between risk perception, spontaneous adaptation behavior to heat waves and heatstroke in Guangdong province, China. BMC Public Health 13:913. https://doi.org/10.1186/1471-2458-13-913

Manoli G, Fatichi S, Schläpfer M, Yu K, Crowther TW, Meili N et al. (2019) Magnitude of urban heat islands largely explained by climate and population. Nature 573(7772):55-60. https://doi.org/10.1038/s41586-019-1512-9

Martens T, Rost J, Gresele C (2014) Bedrohung und Vulnerabilität. Zusammenstellung sozialwissenschaftlicher Items und Skalen. Mora C, Dousset B, Caldwell IR, Powell FE, Geronimo RC, Bielecki CR et al (2017) Global risk of deadly heat. Nat Clim Change 7(107):501-506

Murtagh N, Gatersleben B, Fife-Schaw C (2019) Occupants' motivation to protect residential building stock from climate-related overheating: a study in southern England. J Clean Prod 226:186-194. https://doi.org/10.1016/ j.jclepro.2019.04.080

Projekt Augsburg bleibt cool (2019) Forschungsprojekt Abc. https://uni-ulm.de/ projekt-abc, updated on $3 / 3 / 2020$, checked on $3 / 17 / 2020$.

Rauf S, Bakhsh K, Abbas A, Hassan S, Ali A, Kächele H (2017) How hard they hit? Perception, adaptation and public health implications of heat waves in urban and peri-urban Pakistan. Environ Sci Pollut Res Int 24(11):10630-10639. https://doi.org/10.1007/s11356-017-8756-4

Rogers RW (1975) A protection motivation theory of fear appeals and attitude change. J Psychol 91(1):93-114. https://doi.org/10.1080/ 00223980.1975 .9915803

Rosenstock IM (1974) Historical origins of the health belief model. Health Educ Monogr 2(4):328-335

Rotter JB (1966) Generalized expectancies for internal versus external control of reinforcement. Psychol Monogr 80(1):1-28. https://doi.org/10.1037/ h0092976

Schmitt N (1996) Uses and abuses of coefficient alpha. Psychol Assess 8(4):350-353. https://doi.org/10.1037/1040-3590.8.4.350

Schwaller NL, Kelmenson S, BenDor TK, Spurlock D (2020) From abstract futures to concrete experiences: how does political ideology interact with threat perception to affect climate adaptation decisions? Environ Sci Policy 112:440-452. https://doi.org/10.1016/j.envsci.2020.07.001

Semenza JC, Ploubidis GB, George LA (2011) Climate change and climate variability: personal motivation for adaptation and mitigation. Environ Health 10:46. https://doi.org/10.1186/1476-069X-10-46

Semenza JC, Wilson DJ, Parra J, Bontempo BD, Hart M, Sailor DJ, George LA (2008) Public perception and behavior change in relationship to hot weather 
and air pollution. Environ Res 107(3):401-411. https://doi.org/10.1016/ j.envres.2008.03.005

Smit B, Pilifosova O, Burton I, Challenger B, Huq S, Klein RJT, et al. (2001) Adaptation to climate change in the context of sustainable development and equity. Climate Change 2001: Impacts, Adaptation, and Vulnerability: 877-912.

Taber KS (2018) The use of Cronbach's alpha when developing and reporting research instruments in science education. Res Sci Educ 48(6):1273-1296. https://doi.org/10.1007/s11165-016-9602-2

Tan S (2009) Misuses of KR-20 and Cronbach's alpha reliability coefficients. Egit ve Bilim 34(152):101. https://doi.org/10.1007/s11165-016-9602-2

Tavakol M, Dennick R (2011) Making sense of Cronbach's alpha. Int J Med Educ 2:53-55. https://doi.org/10.5116/ijme.4dfb.8dfd

Terpstra T, Lindell MK (2013) Citizens' perceptions of flood hazard adjustments. Environ Behav 45(8):993-1018. https://doi.org/10.1177/0013916512452427

United Nations, Department of Economic and Social Affairs, Population Division (2019) World urbanization prospects: the 2018 revision. United Nations, Department of Economic and Social Affairs, Population Division.

Valois P, Talbot D, Bouchard D, Renaud J-S, Caron M, Canuel M, Arrambourg N (2020) Using the theory of planned behavior to identify key beliefs underlying heat adaptation behaviors in elderly populations. Popul Environ 41(4):480--506. https://doi.org/10.1007/s11111-020-00347-5

Wang J, Chen Y, Tett SFB, Yan Z, Zhai P, Feng J, Xia J (2020) Anthropogenicallydriven increases in the risks of summertime compound hot extremes. Nat Commun 11(1):528. https://doi.org/10.1038/s41467-019-14233-8

Watts N, Amann M, Arnell N, Ayeb-Karlsson S, Beagley J, Belesova K et al. (2020) The 2020 report of The Lancet Countdown on health and climate change: responding to converging crises. The Lancet. https://doi.org/10.1016/S01406736(20)32290-X

White-Newsome JL, Sánchez BN, Jolliet O, Zhang Z, Parker EA, Dvonch JT, O'Neill MS (2012) Climate change and health: indoor heat exposure in vulnerable populations. Environ Res 112:20-27. https://doi.org/10.1016/ j.envres.2011.10.008

White-Newsome JL, Sánchez BN, Parker EA, Dvonch JT, Zhang Z, O’Neill MS (2011) Assessing heat-adaptive behaviors among older, urban-dwelling adults. Maturitas 70(1):85-91. https://doi.org/10.1016/j.maturitas.2011.06.015

Wolf J, Adger WN, Lorenzoni I, Abrahamson V, Raine R (2010) Social capital, individual responses to heat waves and climate change adaptation: an empirical study of two UK cities. Glob Environ Change 20(1):44-52. https:// doi.org/10.1016/j.gloenvcha.2009.09.004

Wynveen CJ, Wynveen BJ, Sutton SG (2015) Applying the value-belief-norm theory to marine contexts: implications for encouraging pro-environmental behavior. Coast Manag 43(1):84-103. https://doi.org/10.1080/08920753.2014.989149

Yousefpour R, Prinz A, Ng C (2019) Public perceptions of climate change adaptation in Singapore dealing with forecasted sea level rise. Hum Ecol Risk Assess 26(6):1449-1475. https://doi.org/10.1080/10807039.2019.1580140

Zhang L, Ruiz-Menjivar J, Luo B, Liang Z, Swisher ME (2020) Predicting climate change mitigation and adaptation behaviors in agricultural production: a comparison of the theory of planned behavior and the Value-Belief-Norm Theory. J Environ Psychol 68:101408. https://doi.org/10.1016/j.jenvp.2020.101408

Zhao L (2018) Urban growth and climate adaptation. Nat Clim Change 8(12):1034. https://doi.org/10.1038/s41558-018-0348-x

\section{Acknowledgements}

This research was funded by Bundesministerium für Umwelt, Naturschutz und nukleare Sicherheit (German Federal Ministry for the Environment, Nature Conservation and Nuclear Safety), grant number 67DAS144/German Adaptation Strategy to Climate Change).

\section{Funding}

Open Access funding enabled and organized by Projekt DEAL.

\section{Competing interests}

The authors declare no competing interests.

\section{Additional information}

Correspondence and requests for materials should be addressed to Sabrina Katharina Beckmann.

Reprints and permission information is available at http://www.nature.com/reprints

Publisher's note Springer Nature remains neutral with regard to jurisdictional claims in published maps and institutional affiliations.

cc (i) Open Access This article is licensed under a Creative Commons Attribution 4.0 International License, which permits use, sharing, adaptation, distribution and reproduction in any medium or format, as long as you give appropriate credit to the original author(s) and the source, provide a link to the Creative Commons license, and indicate if changes were made. The images or other third party material in this article are included in the article's Creative Commons license, unless indicated otherwise in a credit line to the material. If material is not included in the article's Creative Commons license and your intended use is not permitted by statutory regulation or exceeds the permitted use, you will need to obtain permission directly from the copyright holder. To view a copy of this license, visit http://creativecommons.org/ licenses/by/4.0/.

(c) The Author(s) 2021 